\title{
Who are we?
}

\section{Lalini Rajapaksa}

Former Professor in the Department of Community Medicine, University of Colombo, Sri Lanka

Correspondence: lalinirajapaksa@gmail.com

DOI: https://doi.org/10.4038/jccpsl.v23i4.8134

Received on: 14 November 2017

Accepted on: 5 December 2017

We are members of a college whose antecedents date back to the Society of Medical Officers of Health formed in November 1927. Thus, we become the second oldest professional organisation in Sri Lanka, second only to the Sri Lanka Medical Association established in 1887 as the Ceylon Branch of the British Medical Association. It is also the first documented professional body in public health to be established in the Australasian region. The society underwent several changes of name; in 1960, it became the Ceylon Public Health Association and in 1972, the Sri Lanka Association of Community Medicine. The College of Community Physicians of Sri Lanka (CCPSL) was established in 1995 (1). Members of the CCPSL are specialists in community medicine i.e. consultant community physicians holding varied posts in the Ministry of Health and Academia in Sri Lanka. It therefore behoves us to examine what constitutes 'community medicine'.

The search for a definition of community medicine revealed a number of variations of it. A glossary of terms for Community Health Care and Services for Older Persons produced by the Kobe Centre defines community medicine as "the study of health and disease in the population of a defined community or group and the practice of medicine concerned with groups or populations rather than individual patients" (2). The report of a WHO SEARO study group on teaching of community medicine in undergraduate curricula defined community medicine as "a system of delivery of comprehensive health care to the people by a health team in order to improve the health of the community" (3). The Text Book of Community Medicine defines it as "a discipline that provides comprehensive health services ranging from preventive, promotive, curative to rehabilitative services” (4).

A more recent definition is that given in the sixth edition of 'A Dictionary of Epidemiology' edited by Miquel Porta for the International Epidemiological Association in 2014. It defines community medicine as "an interdisciplinary field that aims at dealing integrally with the preservation and restitution of health, as well as to prevent disease, not only at an individual level but also in groups of defined communities, taking into consideration health and social determinants". It further states that the main goal of community medicine is "to identify health problems and needs, and to evaluate the extent to which clinical and public health services meet such needs” (5).

The term 'community medicine' was formally coined by the Royal Commission on Medical Education, which sat in 1965-68 to review both undergraduate and postgraduate medical education in Great Britain. They defined it as "the specialty practised by epidemiologists and administrators of medical services and by the staff of corresponding academic departments. It is concerned not with the treatment of individual patients but with the broad questions of health and disease in the community at large. In community medicine, as we define it above, the doctor has no monopoly of responsibility or of contribution: many other people’s skills are also required" (6).

Following a key recommendation of the commission, a Faculty of Community Medicine was set up in 1972, as a joint autonomous body by the Royal Colleges of Physicians of London and Edinburgh, 
and the Royal College of Physicians and Surgeons of Glasgow, and certification of specialists in community medicine commenced. The faculty redefined community medicine as "that medical specialty which deals with populations and comprises those doctors who try to measure the needs of the population, both sick and well, who plan and administer services to meet those needs and those who are engaged in research and teaching in the field” (7). In 1989, the Faculty of Community Medicine changed its name to the Faculty of Public Health Medicine. With opening up of the specialty of public health to non-medical professions in 2002, the name was changed to the Faculty of Public Health (8).

The term 'public health' has been in use over a long period of time, from at least the mid-1800s onwards, if not from before that time. There is archeological evidence that ancient civilizations of both the East and the West provided public health services to their populations. What the term 'public health' encompasses has evolved over time with changing hazards to the health of the public and collective action needed to address these issues. Often the interventions were population-based with involvement of the government and exhibited potential for infringement of individual rights for the benefit and protection of the community; features that we see in current public health practice (9).

Public health was defined as early as 1920 by Charles Edward Amory Winslow, the first chair in Public Health at the Yale School of Medicine and remains relevant to date. The definition states that "public health is the science and the art of preventing disease, prolonging life and promoting physical health and efficiency through organized community efforts for the sanitation of the environment, the control of community infections, the education of the individual in principles and personal hygiene, the organization of medical and nursing services for the early diagnosis and preventive treatment of disease, and the development of the social machinery which will ensure to every individual a standard of living adequate for the maintenance of health; organizing these benefits in such a fashion as to enable every citizen to realize his birthright of health and longevity” (10).

Sir Donald Acheson in his report on Public Health in England published in 1988 defined public health as "science and art of preventing disease, prolonging life, and promoting health through the organised efforts of society" (11). This reflects the essential focus of modern public health and the WHO definition has been adapted from the above report (12).

The definitions of public health by Winslow and Acheson, though far apart in time are similar in that they identify preventing disease, prolonging life and promoting health as core-functions of public health to be achieved through organized societal efforts.

In the sixth edition of 'A Dictionary of Epidemiology', public health is defined in much more detail than in the WHO definition (5). It is more comprehensive in that it has been expanded into detailed functions under four dimensions. The preamble to the definition says "public health like most sculptures, symphonies, and other works of art, certain important things in life have several dimensions". The four dimensions are:

1. The health of a whole society. It can be measured and assessed through quantitative and qualitative indicators and analytic processes.

2. The specific policies, services, programs and other essential efforts agreed (ideally, and often, democratically), organized, structured, financed, monitored, and evaluated by society to collectively protect, promote, and restore the people's health and its determinants.

3. The institutions, public and private organizations - including private and public companies, and other citizens organizations, that plan, develop, fund, and implement such efforts, and which are thus an integral part of local, national, regional, and global public health systems.

4. The scientific disciplines and professions, knowledge, methods, art, and craft essential to positively influence health determinants, and thus prevent disease and disability.

The WHO has identified ten core public health functions (13) and the US Government has codified ten essential services (14) that public health agencies and institutions should provide. These documents identify the scope and guidelines for the skills needed for current public health practice. It appears that what public health specialists are required to do fall into three main domains; viz. assessment, policy development 
and assurance. There is no doubt that changing priorities and future challenges would lead to the evolution of the discipline of public health to meet those needs as it has done in the past.

It can be argued that the definition of community medicine provided by the Faculty of Community Medicine is equally applicable to public health especially that of the early period. It appears that each of these disciplines, public health and community medicine had to face substantially different problems at the time the discipline came into being and turned to different methodologies to solve them. The term 'public health' has the advantage that its core functions in the current context are more clearly identified and its flexibility to change with changing needs have been demonstrated over a longer period of time.

It is left to the reader to decide who we are, or what we want to be, Specialists in Community Medicine or Public Health Physicians or does it matter what we call ourselves? In the words of the Bard, "What's in a name? That which we call a rose by any other name would smell as sweet” (15).

\section{References}

1. Journal of the Community Physicians of Sri Lanka 1996; 1(1).

2. WHO Centre for Health Development. A Glossary of Terms for Community Health Care and Services for Older Persons. Ageing and Health Technical Report 2014(WHO/WKC/Tech. Ser. /04.2). Kobe:World Health Organization, 2004.

Available from: http://www.who.int/kobe_centre/ ageing/ahp_vol5_glossary.pdf.

3. WHO SEAR. Report of the Technical Discussions on Teaching of Community Medicine in Undergraduate Medical Education. 25th Session of the WHO Regional Committee for South-East Asia, Colombo (SEA/RC25/15). New Delhi: WHO Regional Office for SEA, 1972.

4. A Textbook of Community Medicine / History of Community Medicine.

Available from: https://en.wikibooks.org/wiki/ A_Textbook_of_Community_Medicine/History_ of_Community_Medicine.

5. Miquel Porta. A Dictionary of Epidemiology (6th edition). A hand book sponsored by the International Epidemiological Association. Oxford: Oxford University Press, 1983.
6. Acheson RM. Medicine, the community, and the university: a century of Cambridge history. British Medical Journal 1978; 2(6154): 1737-1741.

7. Faculty of Community Medicine of the Royal College of Physicians. Standing Orders. London: Faculty of Community Medicine.

8. The Faculty of Public Health of the Royal Colleges of the United Kingdom (Reg. Charity No 263894). Memorandum.

Available from: http://www.fph.org.uk/uploads/ Memorandum_Privy\%20Council.pdf.

9. Johnson JA, Johnson III A, Morrow CB. Historical developments in public health and the 21st century. Available from: http://www.samples.jbpub.com/ 9781449688332/Chapter2.pdf.

10. History of the Yale School of Public Health. Official website.

Available from: http://bulletin.printer.yale.edu/ htmlfiles/publichealth/history-of-the-yale-school-ofpublic-health.html.

11. Acheson D. Independent Inquiry into Inequalities in Health Report. Department of Health and Social Care. The Stationery Office (ISBN 011322173 8).

Available from: https://www.gov.uk/government/ publications/independent-inquiry-into-inequalities-inhealth-report.

12. Martin-Moreno JM. A systematic approach to public health operations and services: towards positive coordination with health care and other services. European Region: World Health Organization, 2011. Available from: http://www.euro.who.int/_data/ assets/pdf_file/0003/135507/JMM_PHS_ strengthenings.pdf?ua $=1$.

13. WHO. Public health services. European Region: World Health Organization.

Available from: http:/www.euro.who.int/en/healthtopics/Health-systems/public-health-services/publichealth-services.

14. CDC. The public health system and the 10 essential public health services. Atlanta: Centre for Disease Control and Prevention.

Available from: https://www.cdc.gov/stltpublichealth/ publichealthservices/essentialhealthservices.html.

15. Romeo and Juliet Quotes by William Shakespeare. Available from: https://www.goodreads.com/work/ quotes/3349450-an-excellent-conceited-tragedie-ofromeo-and-juliet. 